\section{La auditoría de gestión en el Perú y su impacto en el desarrollo empresarial}

\author{
The management audit in Peru and its impact on business \\ development
}

\begin{abstract}
RESUMEN
El presente artículo se desarrolla en función a la importancia y trascendencia de valorar los mecanismos de control previo, concurrente o simultáneo y posterior en la gestión privada y pública del país con el objeto de neutralizar los focos de corrupción y de optimizar la gestión empresarial privada y pública. El Sistema Nacional de Control, que tiene como su organismo rector a la Contraloría General de la República, cuyo ámbito de aplicación es en el sector público nacional, en las últimas décadas no ha cumplido con sus funciones en forma eficiente y eficaz que le fija la Constitución Política del Perú, y sus normas regulatorias, además el Congreso General de la República se regula por su reglamento interno, que tiene fuerza de ley, no permitiendo que la Contraloría General de la República cumpla su función fiscalizadora, la escasez de recursos presupuestales, por estas y otras consideraciones asume un rol precario e intrascendente en la cautela de los recursos nacionales afectando el erario nacional. En la actividad privada el panorama es similar, esta se limita a cumplir con los establecido en el marco legal presentando sus estados financieros auditados en forma anual por empresas o sociedades auditoras privadas nacionales e internacionales. Los filtros de control financiero, económico, administrativo y de gestión son débiles y en algunos casos no reflejan la realidad de la gestión empresarial o institucional. Los auditores en su gran mayoría requieren capacitación, especialización y perfeccionamiento en materia de fiscalización pública y privada, además deben acreditar solvencia moral, ética y deontología profesional, los auditados deben conocer las normas técnicas de control para cumplirlas con rigurosidad, y los resultados finales de las auditorías deben ser objetivos, ajustarse a los procesos técnicos y a la legalidad.
\end{abstract}

Palabras claves: Sistema Nacional de Control; Auditoría Financiera; Auditoría Administrativa; Auditoría de Gestión.

\begin{abstract}
This article is developed based on the importance and significance of assessing the mechanisms of prior, concurrent or simultaneous and subsequent control in the private and public management of the country in order to
\end{abstract}

\section{Luis Fernando Valeriano Ortiz}

lvalerianoo@unmsm.edu.pe Universidad Nacional Mayor de San Marcos, Facultad de Ciencias Administrativas. Lima, Perú

Presentado: 13/03/2020 - Aceptado: 29/10/2020 - Publicado: 26/11/2020

(C) Los autores. Este artículo es publicado por Gestión en el Tercer Milenio de la Facultad de Ciencias Administrativas de la Universidad Nacional Mayor de San Marcos. Este es un artículo de acceso abierto, distribuido bajo los términos de la licencia Creative Commons Atribucion - No Comercia_Compartir Igual 4.0 Internacional. (http://creativecommons.org/licenses/by-nc-sa/4.0/) que permite el uso no comercial, distribución y reproducción en cualquier medio, siempre que la obra original sea debidamente citada. 
neutralize the sources of corruption and to optimize private business management and public. The National Control System, whose governing body is the Comptroller General of the Republic, whose scope of application is in the national public sector, in recent decades it has not fulfilled its functions in an efficient and effective manner established by the Political Constitution of Peru, and its regulatory norms, in addition the General Congress of the Republic is regulated by its internal regulations, which have the force of law, not allowing the Comptroller General of the Republic to fulfill its oversight function, the shortage of budgetary resources, Due to these and other considerations, it assumes a precarious and inconsequential role in the preservation of national resources, affecting the national treasury. In private activity, the panorama is similar, it is limited to complying with those established in the legal framework, presenting its financial statements audited annually by national and international private companies or auditing companies. The financial, economic, administrative and management control filters are weak and in some cases do not reflect the reality of business or institutional management. The vast majority of auditors require training, specialization and improvement in matters of public and private control, in addition they must prove moral solvency, ethics and professional deontology, the auditees must know the technical control standards to comply with them rigorously, and the final results of The audits must be objective, in accordance with technical processes and legality.

Keywords: National System of Control; Financial Audit; Administrative Audit; Management Audit.

\section{INTRODUCCIÓN}

El Perú es un país que en las últimas cuatro décadas viene manteniendo un desarrollo equilibrado y sostenido de sus factores macro económicos, políticos, sociales, regulatorios y ambientales reflejados en sus indicadores más importantes de acuerdos a informes de organismo multinacionales como el Banco Interamericano de Desarrollo (BID), Fondo Monetario Internacional (FMI), Banco Mundial (BM) y la Comisión Económica para América Latina y el Caribe (CEPAL) a nivel internacional y en el ámbito nacional el Banco Central de Reserva (BCR), Instituto Nacional de Estadística e Informática (INEI) y Anuario Estadístico. El desarrollo del Perú está en función a su riqueza de recursos naturales no renovables como es la minería (exportamos cobre, oro, plata, zinc [como materia prima]), sus precios están sujetos a las fluctuaciones del mundo financiero, además estamos incursionando en la exportación de recursos renovables a través de la llamada diversificación productiva como el café, arácnidos, quinua, cacao, espárragos, etc., también la industria pesquera viene exportando sus productos. Este panorama de desarrollo y crecimiento requiere ser reforzado con los mecanismos de calidad y control que respondan a estándares nacionales e internacionales para garantizar transparencia en las operaciones financieras, económicas y administrativas de la gestión pública y privada del país.

El Sistema Nacional de Control de la actividad pública tiene como cabeza de sistema a la Contraloría General de la República (CGR) y a las Oficinas de Auditoría de los Organismo del Estado, quienes cumplen un rol limitado de control previo, concurrente o simultáneo y posterior, reflejados en sus auditorías y exámenes especiales precarias. Debido a que no cuentan con los presupuestos económicos necesarios, normas técnicas de control que cubran a todos los sistemas de la gestión empresarial o institucional y un potencial humano profesional competente que le permitan cumplir una función de fiscalización eficiente y eficaz, donde comprenda a toda la gestión pública del país, preferentemente a los sectores productivos y de servicios que administra el ejecutivo, gobiernos regionales y locales y organismos estratégicos como el Congreso de la República, la Superintendencia Nacional de Aduanas y de Administración Tributaria (SUNAT) y demás organismo reguladores. 
Con respecto al sistema de control en el sector privado podemos mencionar las siguientes precisiones:

Para las empresas o sociedades auditoras externas, las más importantes son de origen internacional globalizadas que prestan sus servicios de auditoría financiera a la CGR y demás organismos del estado y a las empresas privadas, limitándose a la revisión de su gestión contable reflejas en sus balances y sus estados financieros, utilizando normas financieras internacionales.

Las Empresas privadas con excepciones cuentan con Oficinas de Auditoría Interna dentro de su organización empresarial, solo les interesa la rentabilidad empresarial, es más para algunas la consideran como un sobre costo dentro de su gestión, grave error porque de contar con los mecanismos de control interno multiplicarían sus utilidades. Arens, Elder y Beasley (2007) señalan que "el objeto de la auditoría es reducir el riesgo de información, lo cual disminuye el costo de obtener capital" (p. 18). Además, Amador (2008) refiere que:

Las auditorías interna y externa representan un fuerte apoyo para la alta gerencia, que al contar con una u otra tiene la seguridad de que la vigilancia de su actividad financiera y administrativa se está efectuando a tiempo, con oportunidad y resultados. (p. 8)

La auditoría hoy en día, no es patrimonio de ninguna carrera profesional, es ejercida por un estanque polivalente de profesionales especializados en sistema de control. Para Sandoval (2012) la auditoría constituye:

Un apoyo a todos los miembros de la organización, ya que durante el desempeño de su trabajo sus propios conocimientos, experiencia y formación académica y profesional, le permite estar en condición de externar opiniones, posturas y procedimientos en beneficio de la organización. (p. 37)

\section{OBJETIVO DEL ARTÍCULO}

Es articular el Sistema Nacional de Control de la gestión pública con la empresa privada para garantizar mayor transparencia en las operaciones contables, financieras, administrativas y de gestión, que redunden en la calidad del servicio público en las entidades públicas y en la calidad de los productos que desarrollo el sector privado, reflejados en estados financieros rentables.

\section{ARGUMENTACIÓN}

El Sistema Nacional de Control del país requiere de una reingeniería, de acuerdo al avance de la ciencia, tecnología y humanidades de un mundo globalizado, recogiendo experiencias exitosas de países desarrollados en materia de control de la gestión pública y privada y con normas técnicas de control que comprendan a toda la gestión empresarial.

\section{Análisis de Macro Entorno Nacional.}

\section{Factor Político.}

La clase política del país debe acreditar solvencia moral, ética y deontología profesional en el ejercicio de la función pública. En caso de cometerse delitos que afecten el patrimonio del estado se les debe aplicar muerte civil para que nunca puedan ejercer función pública, independientemente de los procesos administrativos y judiciales. La CGR debe contar con un registro informático de los funcionarios sancionados en la vía administrativa y el Poder Judicial de aquellos procesados y sentenciados en la vía judicial a las que tengan acceso las personas jurídicas y naturales del país que lo requieran. De igual forma las empresas proveedoras privadas sancionadas en una o en ambas vías deben estar impedidas de ser contratadas como proveedoras del Estado.

\section{Factor Económico.}

El crecimiento de la economía del país, que podría ser mejor, reflejados en el Producto Bruto Interno (PBI), está en función sustantiva en la transparencia económica de la gestión pública y privada en sus operaciones contables, financieras, bursátiles y presupuestales reflejadas en sus documentos de gestión. El Sistema Nacional de Control debe cautelar rigurosamente el cumplimiento de la legislación nacional, de los principios y normas técnicas de los sistemas de contabilidad, finanzas, bolsa de valores y de la programación, ejecución y evaluación presupuestal en cada periodo. En ese mismo sentido, 
las entidades del estado que correspondan como la CGR, SUNAT, Superintendencia de Mercado de Valores y otras, deben cruzar información y verificar la veracidad de los estados financieros que presenten las empresas privadas por mandato de ley. El lavado de activos es el peor flagelo que afecta la moral y la economía del país y no se cuenta con la cantidad y calidad con profesionales especializados en la materia.

\section{Factor Educativo.}

El Sistema Educativo en materia de control requiere contar con profesionales altamente especializados en auditoría para los Auditores Seniores y Juniores. Teniendo en cuenta que el Centro Nacional de Planeamiento Estratégico (CEPLAN, 2011) indica que "en el Perú la distribución de los profesionales por ocupación principal no ha variado en las últimas décadas y permanece concentrada en las profesiones de Derecho, Ciencias Sociales y Humanidades..." (p. 62).

En ese sentido, se hace necesario que se implementen Programas de Posgrado de Maestría con mención en Control Gubernamental y de Auditorías; así como curso de especialización, sería recomendable crear una Universidad especializada. La CGR cuenta con la Escuela Nacional de Control, sus actividades académicas no son de nivel de pos y pre grado, sino de perfeccionamiento, se requiere mayor descentralización a nivel nacional, preferentemente en las veinticinco regiones del país, la capacitación es tanto para los auditores como para los auditados. Las universidades privadas no priorizan esta mención en sus programas de posgrado, la Universidad Nacional Mayor de San Marcos (UNMSM) en su Facultad de Ciencias Contables cuenta con una mención en sus programas de Maestría.

\section{Factor Ambiental.}

El Sistema Nacional de Control y las sociedades de auditoría deben incorporar normas técnicas de control que protejan el medio ambiente y la conservación del ecosistema del país, fijando estándares ambientales, que recojan indicadores internacionales y velando que los contratos de explotación de los recursos suscritos entre el estado y las empresas privadas nacionales e internacionales incluyan cláusulas de conservación y protección del medio ambiente y sus penalidades en caso de incumplimiento.

\section{Factor Gestión de la Calidad.}

Este factor estratégico que es tan importante como la evaluación financiera, no tiene la relevancia en materia de control interno y externo al evaluar la gestión, por no contar con normas técnicas de control donde se establezcan estándares para medir la calidad de los productos y servicios que ofertan las entidades del estado y las empresas privadas a sus usuarios o clientes.

\section{Factor Regulatorio.}

Se requiere una revisión integral de la legislación en materia de control, desde la Constitución Política del Estado, Ley Orgánica del Sistema Nacional de Control, Reglamento de Organización y Funciones de la CGR y de las Sociedades de Auditoría para adecuarlas a una nueva visión, misión y valores que deben asumir para combatir las malas prácticas de la gestión empresarial, que incluya a todos los procesos técnicos que serán materia de auditoría o exámenes especiales, no solo limitándose a la evaluación de los estados financieros.

\section{Factor Tecnológico.}

La ciencia, tecnología y las humanidades avanzan vertiginosamente, dentro de ellas están las tecnologías de la información y comunicaciones que permiten a la gestión de las entidades optimizar sus recursos empresariales, contando con un sistema de información gerencial para la toma de decisiones en tiempo real y virtual. Las acciones de control deben ejecutar sus funciones empleando equipos y programas informáticos de última generación para garantizar mayor objetividad y transparencia en su función fiscalizadora.

\section{Análisis del Macro Entorno Internacional.}

\section{Factores Globales.}

El Sistema Nacional de Control del Estado y las Sociedades de Auditoría en el sector privado deben contar con Normas Técnicas de Control, que respondan a las exigencias empresariales de un mundo globalizado en su labor fiscalizadora en la gestión empresarial. 


\section{CONCLUSIONES}

- La Constitución Política del Perú de 1993 requiere ser modificada en sus artículos pertinentes en materia del sistema nacional de control, esta tiene una vigencia de más de 25 años.

- Fortalecimiento del sistema nacional de control asignándoles mayores recursos para que cubra su acción de control previo, concurrente o simultáneo y posterior a las 25 regiones del país, los gobiernos locales, empresas del estado y organismos autónomos.

- Ninguna entidad del estado debe estar excluida de la acción de control interno por la CGR.

- Todas las oficinas de control institucional deben depender estructuralmente y funcionalmente de la CGR; así como sus funcionarios.

- El perfil profesional del Auditor debe responder a una formación profesional polivalente del más alto nivel académico, con especialización en auditoría y fundamentalmente no contar con antecedentes penales, judiciales, policiales y procesos judiciales con sentencias o en proceso.
- Los informes de auditoría que contienen observaciones, hallazgos y recomendaciones deben sustentarse en documentación confiable y verificable y no basarse en suposiciones, hipótesis y menos denuncias anónimas. Estos informes deben servir de base para acreditar cualquier denuncia judicial o administrativa de ser el caso.

- Las acciones de control interno deben comprender a todos los procesos técnicos de la gestión empresarial (contable-financiera, administrativa, y de gestión).

\section{REFERENCIAS BIBLIOGRÁFICAS}

Amador, A. A. (2008). Auditoría Administrativa. Proceso y aplicación. México: McGraw-Hill Interamericana Editores.

Arens, A. A., Elder, R. J., \& Beasley, M. S. (2007). Auditoría. Un enfoque integral (11ma edición). México: Pearson Educación.

Centro Nacional de Planeamiento Estratégico (2011). Plan Bicentenario: el Perú hacia el 2021. Recuperado de: https://www.ceplan.gob.pe/ documentos_/plan-bicentenario-el-peru-hacia-el-2021/

Sandoval, H. (2012). Introducción a la Auditoría. Ciudad de México, México: Red Tercer Milenio. 
